\title{
Short term testosterone replacement therapy improves libido and body composition
}

\author{
Reposição de testosterona a curto prazo melhora \\ libido e composição corporal
}

Edésio Seara de Andrade Júnior ${ }^{1}$, Ruth Clapauch', Salo Buksman²

${ }^{1}$ Divisão de Endocrinologia Feminina e Andrologia, Setor de Endocrinologia, Hospital da Lagoa, Rio de Janeiro, RJ, Brasil ${ }^{2}$ Instituto Nacional de Traumatologia e Ortopedia (Into), Ministério da Saúde, Rio de Janeiro, RJ, Brasil

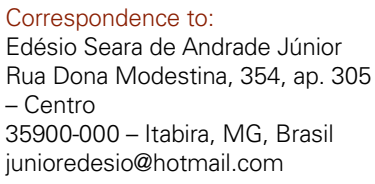

Received on Oct/16/2009 Accepted on Nov/9/2009

\begin{abstract}
Objective: To assess the efficacy and safety of testosterone replacement in males with late-onset hypogonadism compared to hypogonadal men without replacement, and controls, during six months. Methods: We assessed, through ADAM, AMS, IIEF-5 and SF-36 questionnaires, and through clinical and laboratorial examinations, 62 patients divided into three groups: 17 hypogonadal males (HR) used intramuscular testosterone every three weeks; 14 hypogonadal males (HV) and 31 non-hypogonadal males (CV) used oral vitamins daily. Results: When compared to others, HR group obtained libido improvement assessed by ADAM $1(p=0.004)$, and borderline sexual potency improvement assessed by IIEF-5 $(p=0.053)$, besides a decrease in waist circumference after eight weeks $(p=0.018)$. The remaining parameters did not differ between the groups. PSA and hematocrit remained stable in those using testosterone. Conclusion: Six months of testosterone replacement improved sexuality and body composition, with prostatic and hematological safety. Arq Bras Endocrinol Metab. 2009;53(8):996-1004
\end{abstract}

Keywords

Testosterone replacement therapy; late onset hypogonadism; andropause; libido; body composition; waist circumference

\section{RESUMO}

Objetivo: Avaliar a eficácia e a segurança da reposição de testosterona em homens com hipogonadismo tardio comparados a hipogonádicos sem reposição e controles, durante seis meses. Métodos: Mediante os questionários ADAM, AMS, IIEF-5 e SF-36, foram feitos exame clínico e laboratorial em 62 pacientes divididos em três grupos: 17 hipogonádicos (HR) usaram testosterona intramuscular a cada três semanas; 14 hipogonádicos (HV) e 31 não hipogonádi$\cos (\mathrm{CV})$ usaram vitaminas via oral diariamente. Resultados: Comparado aos demais, o grupo HR obteve melhora da libido avaliada pelo ADAM $1(p=0,004)$ e melhora limítrofe da potência sexual avaliada pelo IIEF-5 ( $p=0.053$ ), além de diminuição da cintura a partir da oitava semana ( $p=0,018)$. Os demais parâmetros não foram diferentes entre os grupos. PSA e hematócrito se mantiveram estáveis nos que usaram testosterona. Conclusão: A reposição de testosterona durante seis meses melhorou a sexualidade e a composição corporal, com segurança prostática e hematológica. Arq Bras Endocrinol Metab. 2009;53(8):996-1004

\section{Descritores}

Reposição de testosterona; hipogonadismo masculino tardio; andropausa; libido; composição corporal; circunferência abdominal

\section{INTRODUCTION}

W ith the world population's ageing, some problems previously without much repercussion acquired increased relevance, amongst which the symptoms and consequences of male late-onset hypogonadism.
Although this is a current issue, precise criteria for establishing an accurate diagnosis have not yet been set. It makes it difficult to recognize many of the individuals afflicted, thus delaying an early diagnosis and establishing an efficient treatment. At the same time, many 
individuals with symptoms related to natural ageing are wrongly diagnosed as testosterone deficient.

Considering the present state of diagnostic imprecision, current guidelines recommend an association of clinical and laboratorial factors for diagnosing lateonset male hypogonadism (1). Among the clinical factors, one can emphasize body changes, such as increase in visceral fat and decrease in muscle mass and strength, as well as sexual changes such as decreased libido and erectile dysfunction, amongst others. Diagnostic laboratory dosages are not simple, since serum total testosterone gives results of poor reliability due to the increase in SHBG with age (high binding affinity). For a more reliable diagnosis of suspicious cases, it is important to evaluate levels of free testosterone and bioavailable testosterone (testosterone bound to albumin + free testosterone). However, dosage of free testosterone by radioimmunoassay is not reliable too, and should be determined through the method of equilibrium dialysis or by the calculated free testosterone (2).

Several studies have reported clinical and laboratorial improvement when deficient males are submitted to testosterone replacement, contributing to their quality of life, libido, erectile function and reducing cardiovascular risks (3). Yet, only few studies have compared these effects to those obtained with the use of placebo or other potentially useful drugs. The purpose of the present study was to establish the benefits and risks of testosterone replacement during a period of six months in late-onset hypogonadal males, compared to hypogonadal individuals and controls of same age supplemented with vitamins.

\section{METHODS}

This is a prospective study which gives continuation to previous ones conducted for clinical and laboratorial diagnosis of late-onset male hypogonadism $(4,5)$. In our diagnostic studies, we evaluated two-hundred and sixteen males over 50 years of age at the andrology outpatient clinic of the Hospital da Lagoa, Rio de Janeiro, Brazil. Clinical status compatible with hypogonadism was assessed by three screening questionnaires: ADAM, AMS, and IIEF-5. The ADAM (Androgen Deficiency of the Aging Male) questionnaire comprises 10 questions, suggesting hypogonadism when questions 1 or 7 , or other three questions, except for questions 1 and 7 , are positive (6). The AMS (Aging Male's Symptoms) questionnaire comprises questions involving psycholo- gical, somatic vegetative, and sexual aspects, and the higher the score, the more severe the symptoms presented (none - 17 to 26 points; few symptoms - 27 to 36 points; moderate - 37 to 49 points; severe $\geq 50$ points) $(7,8)$. The IIEF- 5 (International Index of Erectile Function) is a questionnaire validated in Brazil (9) for assessing erectile dysfunction. The higher the scoring in a total of 25 points, the better the sexual function: scores from 22 on are considered normal, without any erectile dysfunction (ED); between 17 and 21 , mild ED; between 12 and 16, mild to moderate ED; between 8 and 11 , moderate ED; and between 5 and 7 , severe ED. The laboratorial criterion used to define late-onset male hypogonadism was calculated free testosterone by Vermeulen's formula $<6.5 \mathrm{ng} / \mathrm{dL}$ in two samples collected for total testosterone, albumin and SHBG, over 30 days from each other $(10,11)$.

Using the above criteria, 62 patients were selected for the present study, as 31 of them were hypogonadal and 31 non-hypogonadal controls of same age. All patients were informed on the purposes of the research and its potential benefits as well as of adverse effects of the drugs, and a written consent was signed by all, according to the terms established by the project approved by the Ethics Committee.

All hypogonadal patients were thoroughly assessed for testosterone replacement, through medical history, complete physical and prostate examination, as well as hematocrit, total and free PSA, performed at the Hospital da Lagoa laboratory. Hematocrit was measured by automated counting, with reference values varying from $41 \%$ to $53 \%$. Total and free PSA were determined by the method of electrochemiluminescence. Reference value for total PSA is up to $4.0 \mathrm{ng} / \mathrm{mL}$ and for free PSA is up to $0.9 \mathrm{ng} / \mathrm{mL}$. All hypogonadal patients were submitted to a prostate digital rectal examination at the Urology outpatient clinic of the Hospital da Lagoa during baseline assessment. Control patients underwent the same examinations, except for the prostate digital rectal examination, which was offered but not mandatory.

Hypogonadal patients were then subdivided into two groups: individuals with some contraindication for hormone replacement, such as sleep apnea, history of prostate cancer or benign prostate hyperplasia associated with obstructive symptoms, polycythemia, gynecomastia or abnormal findings in the digital rectal examination, and those who did not wish to start on hormone replacement, even without any contraindica- 
tion, were set in the hypogonadal group that would be only followed-up, without testosterone replacement.

Thus, we obtained three distinct groups: hypogonadal males apt to start testosterone replacement (HR, $\mathrm{n}=17$ ), hypogonadal males who would not receive testosterone replacement $(\mathrm{HV}, \mathrm{n}=14)$, and non-hypogonadal controls $(\mathrm{CV}, \mathrm{n}=3 \mathrm{l})$. The hormone used for replacement was testosterone cypionate, $200 \mathrm{mg}$ every three weeks starting after baseline assessment in group HR. Groups HV and CV (hypogonadal without replacement and controls) used one pill of the same oral vitamin-B complex daily, from baseline assessment on. The study lasted 24 weeks. Follow-up comprised 4 different evaluations for all patients:

- Baseline: following parameters were assessed: weight, waist circumference, hip circumference, laboratory evaluation (glucose, lipids, total and free testosterone, SHBG, hematocrit, total and free PSA), besides completing the ADAM, IIEF, AMS, and SF-36 questionnaires.

- 8 weeks: clinical evaluation (weight, waist and hip circumferences) only.

- 16 weeks clinical evaluation (weight, waist and hip circumferences) plus lipids, glucose, total and free PSA, and hematocrit dosages.

- 24 weeks: weight, waist and hip circumference measurements; ADAM, AMS, IIEF, and SF-36 questionnaires; serum dosages of lipids, hematocrit, PSA, glucose.

Weight was measured with the same conventional anthropometric scales (Filizola) standardized; the patient was supposed to be without shoes and dressed in light outfit. Waist circumference was measured halfway between the last rib and the iliac crest, and the hip had as reference the widest local diameter at the major trochanters (12). Both measurements were always made by the same professional. The waist-hip ratio was established by dividing the measurements of the waist and hip.

SF-36 questionnaire on quality of life, validated for Brazil (13), comprises 11 questions in 8 different dimensions (functional capacity, physical aspects, pain, general health status, vitality, social aspects, emotional aspects, and mental health). Each dimension presents scores from 0 to 100; the higher the scoring, the better is the quality of life in that aspect.

The statistical analysis was performed by the following methods:

- To compare continuous (numeric) variables of groups (with replacement, without replacement, and control), one-way analysis of variance (ANOVA) or Kruskal-Wallis nonparametric ANOVA were used. Tukey's test or nonparametric multiple comparisons test based on Kruskal-Wallis statistics were applied to identify which groups differed from others;

- To compare categorical (qualitative) variables, chi-square $\left(\chi^{2}\right)$ test or Fisher's exact test was used;

- To analyze the behavior of variables along the time (three or four observations) separately by group, an analysis of variance for repeated measurements or Friedman's nonparametric ANOVA were used. Bonferroni's multiple comparisons test (adjusted for repeated measurements) was used to identify which observations differ from others; and, to identify whether the behavior along the time is different between the groups, an analysis of variance for repeated measures on one factor was performed;

- To verify if there is a significant variation in numerical data between two observations, a Wilcoxon signed-rank test was used, and for categoric data, a corrected McNemar test was applied.

We used nonparametric data because some variables did not show normal distribution (Gaussian distribution), due to data dispersion and/or lack of distribution symmetry. The criterion used for determination of significance was $5 \%$. Statistical analysis was performed with the SAS 6.04 software (SAS Institute, Inc., Cary, North Carolina).

\section{RESULTS}

Mean age of the total sample was $70.6 \pm 6.1$ years, and mean BMI was $25.86 \pm 4.17 \mathrm{~kg} / \mathrm{m}^{2}$. At baseline, mean waist and hip circumferences and waist-hip ratio were $95.8 \pm 11.6 ; 94.8 \pm 8.7$; and $1.009 \pm 0.05 \mathrm{~cm}$, respectively. Questionnaires showed the following data: average scoring of total ADAM (except for questions 1 and 7) was $3.6 \pm 2.2$; average AMS scoring was $37.6 \pm 11.3$ and IIEF scoring was $13.4 \pm 7.6$.

At baseline evaluation, there was no difference among groups with regard to age, BMI, waist, hip, waist-to-hip ratio, hematocrit dosage, biochemical parameters, PSA, and total scores in ADAM, IIEF, and AMS, as previously published (4). The only variable that showed a significant difference at baseline was dimension 8 of the SF-36 questionnaire, which is related to mental health, and has evidenced a high score in the 
hypogonadal group that would begin replacement therapy $(\mathrm{HR})$ in relation to the non-hypogonadal control group $(\mathrm{CV})(\mathrm{p}=0.008)$. This difference shows that at the initial evaluation HR group presented better quality of life in terms of mental health (Table 1).

Table 1. SF-36 Health Survey, domain 8 (Mental Health) scores: baseline comparison between the groups

\begin{tabular}{lcccc}
\hline & Group & Mean & $\begin{array}{c}\text { Standard } \\
\text { Deviation }\end{array}$ & Median \\
\hline SF-36 domain 8 & HR & $79.8^{*}$ & 16.5 & 84 \\
(Mental Health) & HV & 70.0 & 22.1 & 74 \\
& CV & 60.5 & 21.6 & 60 \\
\hline
\end{tabular}

${ }^{*} \mathrm{p}=0,008$ for the comparison between groups HR and CV.

During temporal evolution, weight did not show any significant changes, remaining stable in the three groups. HR group showed a significant decrease in waist circumference $(\mathrm{p}=0.018)$ after eight weeks, while this measurement remained stable in HV group, with a slight trend to increase $(\mathrm{p}=0.064)$. However, in group CV there was a significant increase $(\mathrm{p}=0.0001)$ in the waist measurement (Figure 1 ). When considering waist-to-hip ratio, only $\mathrm{CV}$ group showed a significant increase during the entire follow-up period $(\mathrm{p}=0.001)$.

Total cholesterol, HDL, triglycerides, total PSA, and glucose dosages did not change during the study period in neither of the groups. With regard to hematocrit, groups HV and CV showed a significant decrease between baseline assessment and the assessments at 16 and 24 weeks after the beginning of the study $(\mathrm{p}=0.0009$ and $\mathrm{p}=0.0001$, respectively). Group HR showed stable hematocrit (Table 2). Average PSA levels in group HR were $1.29 \pm 0.7 \mathrm{ng} / \mathrm{mL}$ at baseline and $1.89 \pm 1.5 \mathrm{ng} / \mathrm{mL}$

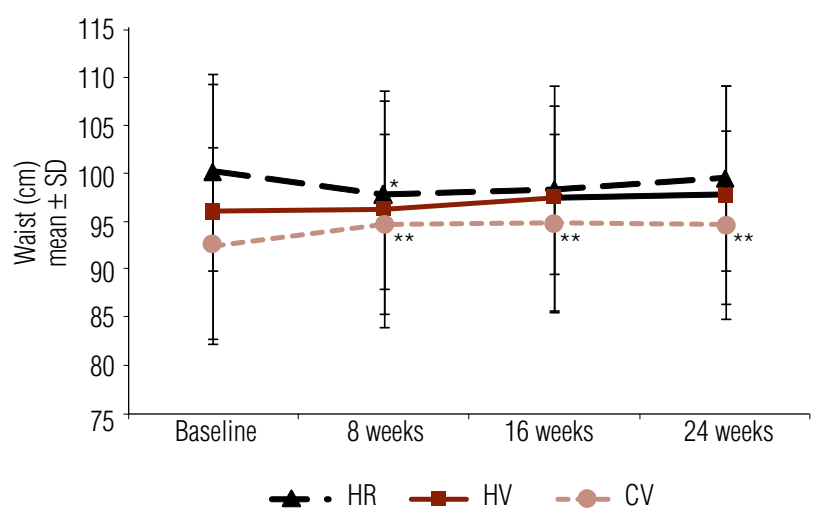

Figure 1. Waist changes during follow-up among groups.

* Significant decrease in the group HR at 8 weeks $(p=0,018) .{ }^{*}$ Significant increase in the group CV at 8, 16 and 24 weeks in comparison to the baseline waist measurement.

In the group HV the waist did not change $(p=0,064)$. $(\mathrm{p}=0.7 \mathrm{l})$ at the end of 24 weeks. In group $\mathrm{CV}$, they varied from $2.38 \pm 4.27$ to $2.89 \pm 5.39 \mathrm{ng} / \mathrm{mL}$ ( $\mathrm{p}=$ $0.25)$. Group HV showed higher average PSA baseline levels (mean $3.26 \pm 3.89 \mathrm{ng} / \mathrm{mL}$ ), which at the end of 24 weeks changed to $2.31 \pm 3.01 \mathrm{ng} / \mathrm{mL}(\mathrm{p}=0.15)$.

When resubmitting the questionnaires used for screening hypogonadism to the patients at the end of 24 weeks, total ADAM (except for questions 1 and 7 ) showed a significant score decrease - reflecting milder symptoms - in groups HR and CV ( $p=0.001$ and $\mathrm{p}=0.004$, respectively). The same difference was observed in AMS $(\mathrm{p}=0.003$ for group HR and $\mathrm{p}=0.002$ for group CV).

When ADAM question 1, referring to decreased sexual desire affirmative, was analyzed independently, a significant change was reported only in group HR $(\mathrm{p}=0.004)$. Question 7 of ADAM, referring to sexual potency decrease, did not show this same difference between groups (Table 3 ).

IIEF questionnaire, used specifically for assessing erectile dysfunction, showed a significant decrease at the end of the 24 weeks, which reflects a deterioration of the erectile function, only in the HV group $(\mathrm{p}=0.017)$. No change was reported in the other two groups.

With regard to quality of life assessed by the SF-36 questionnaire, the following results were observed:

- Dimension 6, related to social function, showed a significant increase in groups HR and CV $(\mathrm{p}=$ 0.039 and $p=0.014$, respectively).

- Dimension 7, related to emotional aspects, showed a significant increase in group CV $(\mathrm{p}=$ $0.001)$.

No differences were observed in the other dimensions after 24 weeks of follow-up.

The groups were further compared with regard to the delta, or difference, between the four questionnaire scores, at the baseline evaluation and after 24 weeks of follow-up. We found a borderline difference only in the variation of IIEF among the groups: scoring increased in HR group, reflecting an improvement in erectile function, while in the remaining groups it decreased $(\mathrm{p}=0.053)$, reflecting a differed evolution among the groups during follow-up (Table 4).

\section{DISCUSSION}

In males older than 40 years old, testosterone may decrease at a rate of 1 to $2 \%$ per year, and it has been reported that over $50 \%$ of 80 -year-old males have testostero- 
Table 2. Hematocrit changes during follow-up and comparison between the groups

\begin{tabular}{|c|c|c|c|c|c|}
\hline Group & Evaluation & Mean (\%) & SD & p-value & $\begin{array}{l}\text { Significant } \\
\text { differences }\end{array}$ \\
\hline \multirow{3}{*}{$H R$} & Baseline & 43.7 & 2.5 & \multirow{3}{*}{0.89} & \\
\hline & 16 weeks & 43.4 & 3.8 & & \\
\hline & 24 weeks & 43.4 & 4.7 & & \\
\hline \multirow{3}{*}{ HV } & Baseline & 42.9 & 2.8 & \multirow{3}{*}{0.0009} & Baseline versus \\
\hline & 16 weeks & 39.6 & 4.2 & & 16 weeks \\
\hline & 24 weeks & 39.6 & 3.5 & & 24 weeks \\
\hline \multirow{3}{*}{ CV } & Baseline & 44.0 & 3.6 & \multirow{3}{*}{0.0001} & Baseline versus \\
\hline & 16 weeks & 42.3 & 3.9 & & 16 weeks \\
\hline & 24 weeks & 42.0 & 3,6 & & 24 weeks \\
\hline
\end{tabular}

Table 3. ADAM questionnaire considered positive by answer yes to items 1 (decrease in libido) or 7 (less strong erections): absolute and percent numbers at baseline and after 24 weeks in the three groups

\begin{tabular}{lcccccc}
\hline \multirow{2}{*}{$\begin{array}{l}\text { Positive } \\
\text { answer }\end{array}$} & \multirow{2}{*}{ Group } & \multicolumn{2}{c}{ Baseline } & \multicolumn{2}{c}{$\mathbf{2 4}$ weeks } & p-value \\
\cline { 3 - 6 } & & $\mathbf{n}$ & $\mathbf{\%}$ & $\mathbf{n}$ & $\mathbf{\%}$ & \\
\hline ADAM 1 & HR & 12 & 70.6 & 2 & 11.8 & $\mathbf{0 . 0 0 4}$ \\
$\begin{array}{l}\text { (Decreased } \\
\text { in libid0) }\end{array}$ & HV & 9 & 64.3 & 8 & 57.1 & 1.00 \\
& CV & 20 & 64.5 & 16 & 51.6 & 0.28 \\
ADAM 7 & HR & 15 & 88.2 & 10 & 58.8 & 0.073 \\
$\begin{array}{l}\text { (Less } \\
\text { strong } \\
\text { erections) }\end{array}$ & HV & 13 & 92.9 & 12 & 85.7 & 1.00 \\
\hline
\end{tabular}

ne levels compatible with hypogonadism (14). Many of the signs and symptoms that comprise the hypogonadal status resemble ageing, like decrease in muscle mass, bone mass, energy, and libido, and fatigue, amongst others (14-16). AMS and ADAM questionnaires show low specificity, thus restricting their applicability for the clinical diagnosis of late-onset male hypogonadism, as recommended by several societies consensus $(1,6,7)$, a conclusion to which we also came (4). However, they may be useful in treatment follow-up. According to the latest consensus (1), late onset hypogonadism diagnosis should be clinical and laboratorial. Total testosterone level looses its reliability as a marker due to the increase in SHBG with age (17); therefore, we used as laboratory criterion the decrease in free testosterone calculated by Vermeulen's formula at two occasions.

In order to clear any doubts regarding the true benefits of testosterone replacement, we compared hypogonadal men who received testosterone replacement (HR) to a hypogonadal group (HV) and a eugonadal group $(\mathrm{CV})$ of same age and BMI who received only
complex-B vitamins. Thus, we were able to separate what was caused by male hormone replacement in deficient men, comparing to the evolution of deficient and control males who did not receive testosterone replacement, and whose effects could be only a result of increased attention and follow-up (placebo effect). In fact, we did not give placebo to groups $\mathrm{HV}$ and $\mathrm{CV}$, but rather complex-B vitamins, for the study was not blind and we wanted to provide the patients with some hope that the medication would improve their symptoms.

During baseline evaluation, we noticed that HR individuals showed a better quality of life in the dimension mental health (SF-36 item 8) when compared to controls. It may be due to the fact that testosterone is a hormone related to impatience and aggressiveness $(18,19)$. Therefore, testosterone-deficient males might have been perceived as having better mental health, particularly the group that agreed to replacement therapy. In our 24-week analysis, the difference in topic 8 of the SF-36 questionnaire was neither maintained nor was there any clear change in the quality of life evaluated through the parameters of questionnaire SF-36 for group $\mathrm{HR}$, when compared to groups $\mathrm{HV}$ and $\mathrm{CV}$. The lack of perception of an evident quality of life benefit may be a limiting factor for patients to continue with testosterone replacement. We noted equivalent improvements in the SF-36 parameters in all groups, which might have been a result of close follow-up of all patients. Follow-up effect may also have occurred with total ADAM and AMS questionnaires. At the end of 24 weeks, we noted, for both groups, that total ADAM (except for questions 1 and 7), showed a significant decrease in the scoring, reflecting milder symptoms $(\mathrm{p}=$ 0.001 and $p=0.004$, respectively). The same change was seen in AMS ( $\mathrm{p}=0.003$ for the HR group, and $\mathrm{p}=$ 0.002 for the CV group).

When separately analyzed, ADAM question 1, specifically related to the decrease in sexual desire, showed a significant change during follow-up only in group HR $(\mathrm{p}=0.004)$. Our findings corroborate information reported in the literature that indicate increase in libido as a benefit of testosterone replacement. In other studies, such as that of Cleveland in 2005, besides an improvement in body composition, cognitive aspects and quality of life, a significant improvement in the sexual desire of hypogonadal males undergoing testosterone replacement was noted. This criterion obtained higher level of evidence of improvement related to replacement than erectile dysfunction alone (20). ADAM question 


\begin{tabular}{|c|c|c|c|c|c|}
\hline $\begin{array}{l}\Delta 24 \text { weeks- } \\
\text { baseline }\end{array}$ & Group & Mean & SE & Median & p-value \\
\hline \multirow{3}{*}{$\begin{array}{l}\text { ADAM total (except } \\
\text { questions } 1 \text { and } 7 \text { ) }\end{array}$} & $\mathrm{HR}$ & -1.35 & 0.39 & -1 & \multirow{3}{*}{0.067} \\
\hline & $\mathrm{HV}$ & 0.07 & 0.40 & 0 & \\
\hline & CV & -1.13 & 0.38 & -1 & \\
\hline \multirow{3}{*}{ AMS } & $H R$ & -9.00 & 2.49 & -7 & \multirow{3}{*}{0.26} \\
\hline & HV & -2.64 & 1.71 & -3.5 & \\
\hline & CV & -6.29 & 1.89 & -9 & \\
\hline \multirow{3}{*}{$\begin{array}{l}\text { IIEF } 5 \\
\text { (Sexual function) }\end{array}$} & $\mathrm{HR}$ & 2.41 & 1.44 & 2 & \multirow{3}{*}{0.053} \\
\hline & HV & -2.07 & 0.80 & -1 & \\
\hline & CV & -0.52 & 0.93 & 0 & \\
\hline \multirow{3}{*}{$\begin{array}{l}\text { SF-36 } 1 \\
\text { (Physical } \\
\text { functioning) }\end{array}$} & $\mathrm{HR}$ & 2.94 & 3.69 & 0 & \multirow{3}{*}{0.24} \\
\hline & HV & 2.14 & 5.44 & 5 & \\
\hline & CV & -3.77 & 2.54 & -5 & \\
\hline \multirow{3}{*}{$\begin{array}{l}\text { SF-36 } 2 \\
\text { (Role-physical) }\end{array}$} & $H R$ & 14.71 & 10.73 & 0 & \multirow{3}{*}{0.71} \\
\hline & HV & 26.79 & 10.95 & 0 & \\
\hline & CV & 8.79 & 6.68 & 0 & \\
\hline \multirow{3}{*}{$\begin{array}{l}\text { SF-36 } 3 \\
\text { (Pain) }\end{array}$} & $H R$ & -3.35 & 5.72 & 0 & \multirow{3}{*}{0.66} \\
\hline & HV & -4.00 & 4.43 & -0.5 & \\
\hline & CV & -0.48 & 3.74 & 0 & \\
\hline \multirow{3}{*}{$\begin{array}{l}\text { SF-36 } 4 \\
\text { (General health) }\end{array}$} & $\mathrm{HR}$ & 0.59 & 5.82 & -5 & \multirow{3}{*}{0.83} \\
\hline & HV & 1.64 & 5.26 & 0 & \\
\hline & CV & 1.45 & 4.06 & -3 & \\
\hline \multirow{3}{*}{$\begin{array}{l}\text { SF-36 } 5 \\
\text { (Vitality) }\end{array}$} & $\mathrm{HR}$ & 4.71 & 4.57 & 5 & \multirow{3}{*}{0.56} \\
\hline & HV & 6.43 & 4.90 & 2.5 & \\
\hline & CV & -1.74 & 4.10 & 5 & \\
\hline \multirow{3}{*}{$\begin{array}{l}\text { SF-36 } 6 \\
\text { (Social } \\
\text { functioning) }\end{array}$} & $\mathrm{HR}$ & 10.29 & 4.18 & 0 & \multirow{3}{*}{0.71} \\
\hline & HV & 4.46 & 5.01 & 0 & \\
\hline & CV & 9.27 & 3.52 & 0 & \\
\hline \multirow{3}{*}{$\begin{array}{l}\text { SF-36 } 7 \\
\text { (Role-emotional) }\end{array}$} & $H R$ & 4.47 & 6.28 & 0 & \multirow{3}{*}{0.26} \\
\hline & HV & 26.21 & 12.22 & 0 & \\
\hline & CV & 22.71 & 6.25 & 0 & \\
\hline \multirow{3}{*}{$\begin{array}{l}\text { SF-36 } 8 \\
\text { (Mental health) }\end{array}$} & $H R$ & 2.06 & 5.30 & 4 & \multirow{3}{*}{0.87} \\
\hline & HV & 5.71 & 6.51 & 2 & \\
\hline & CV & 5.79 & 4.00 & 4 & \\
\hline
\end{tabular}

$\triangle 24$ weeks-baseline: delta (difference) of the score obtained after 24 weeks from the baseline score. SE: Standard Error.

1, which approaches sexual desire decrease, was considered in a previous study conducted by our group (4) as the most reliable for hypogonadism screening. When we prospectively analyzed this question after testosterone replacement in hypogonadal males, we confirmed a significant improvement, reinforcing its reliability for diagnosis and follow-up of late-onset hypogonadism as suggested by several studies (21). Testosterone serum levels associated with decrease in libido may vary from individual to individual. It has been demonstrated that there is no specific cut-off point from which decreased serum testosterone would lead to a decreased sexual desire (22). Therefore, it is sometimes difficult to identify when decreased libido is a symptom of hypogonadism, particularly in older individuals. A study conducted in New Zealand to analyze how sexual function and libido behave before and after testosterone replacement in hypogonadal and eugonadal men found a significant improvement after normal testosterone serum levels had been achieved only in the first group. At the same time, their female partners experienced a decrease in pain, higher satisfaction and an improvement in sexual function after the treatment of their partners (23).

We also noticed as a less evident benefit from testosterone replacement a slight increase in sexual potency, observed through IIEF delta when comparing baseline and after 24 weeks scores, being the delta higher in the HR group when compared to the other two groups. In the last five decades, there was a significant increase in the number of individuals with erectile dysfunction complaints (24), thus increasing the interest in efficient treatments for improving this condition. Studies with testosterone have had conflicting results iconcerning this topic. Some studies have corroborated our findings, such as the one recently conducted in Taiwan, where IIEF was applied before and after testosterone replacement in 20 males proven to be hypogonadal and who showed an improvement in sexual dysfunction evidenced by improved erection (25). Many studies showed a short-term improvement in the erectile dysfunction, and some authors reported an improvement of approximately $50 \%$ in sexual potency and libido (26), also observed by our group. However, erectile dysfunction may be due to many causes. The Endocrine Society recommends in its guidelines that testosterone replacement should be offered only to patients with proven testosterone deficiency, and that the basic cause for hormonal dysfunction should be established (27).

Our results demonstrate that short-term testosterone replacement was beneficial in changing body composition. It reduced significantly the waist circumference without changing weight, which may be interpreted as a potential decrease in cardiovascular risk. Other authors have demonstrated that male waist circumference is inversely correlated to testosterone serum level (28) and that testosterone replacement is directly correlated to a decrease in fat mass and an increase in muscle mass and strength (17). Observational studies have demons- 
trated that low testosterone levels are related to diabetes mellitus, visceral obesity, coronary artery disease, and metabolic syndrome, and that testosterone replacement improves insulin sensitivity in males, thus improving glucose control and reducing visceral obesity $(29,30)$ in diabetic patients. There is evidence that, besides metabolic syndrome being a consequence of late-onset hypogonadism, it may also be a cause, and appropriate changes in life style may prevent not only an evolution towards diabetes, but also towards testosterone deficiency in middle-aged males (31). Some authors suggest that testosterone serum level may be considered as a diagnostic parameter for metabolic syndrome, and that testosterone replacement in these individuals may be efficient in reducing potential risks associated (32). A study with prostate cancer patients turned hypogonadal after GnRH agonists treatment confirmed an increase in fat mass and a decrease in insulin sensitivity, with increased risk of developing type 2 diabetes mellitus (33). Another study demonstrated that testosterone replacement improved glucose levels and body composition, decreasing visceral fat (34) in middle-aged men with type 2 diabetes and mild androgen deficiency.

When evaluating anthropometric measurements during follow-up, we observed that in group HR there was an early decrease in waist circumference, i.e. after eight weeks, and that during subsequent evaluations, this measurement had stabilized; on the other hand, waist circumference remained unchanged in group HV and increased significantly in group CV. Weight did not change in the three groups during follow-up. The same variation in waist circumference was demonstrated by our group in postmenopausal women, at the beginning of hormone replacement therapy (35). With regard to waist-to-hip ratio, some studies have shown that testosterone replacement rapidly improved this ratio, particularly when associated with regular physical exercise (36), thus representing an important parameter for metabolic syndrome improvement.

Despite body composition changes, total cholesterol, HDL, triglycerides and glucose dosages remained unaltered during the 24 weeks period. A limitation of our study is to know whether the body composition change seen with testosterone replacement would have any effect on metabolic parameters on a longer run.

During the six months of follow-up, testosterone replacement showed to be safe. There was neither hematocrit nor PSA increase in males under replacement, which would represent a higher risk of polycythemia, prostate hyperplasia or malignancy related to the treatment. Polycythemia is a well-known complication reported in many studies on testosterone replacement, and it must be taken into account, since hematocrit values above $51 \%$ may increase the frequency of thromboembolic phenomena (37); however, therapy withdrawal is, in most cases, not necessary for this reason. Hajjar and cols. (38), on a retrospective study analyzing testosterone replacement in 45 hypogonadal old males, demonstrated that $24 \%$ of the patients developed polycythemia sufficient for undergoing phlebotomy or temporary interruption of testosterone replacement, and that a third of the cases occurred up to one year after beginning of hormone therapy. On the contrary, in our patients, elderly Brazilian males with a nutritional profile probably different from that of other studies, we observed a decrease in the hematocrit in those men belonging to groups $\mathrm{HV}$ and $\mathrm{CV}$ - using only complex $\mathrm{B}$ vitamins -, and hematocrit stability in hypogonadal males on testosterone replacement.

Total PSA dosages remained stable during the study in all groups. Group HV showed higher baseline PSA levels (mean $3.26 \pm 3.89 \mathrm{ng} / \mathrm{mL}$ ), with digital rectal examination compatible with prostate hyperplasia and mild obstructive signs, which was precisely the treatment contraindication in most cases. None of the patients had a history or suspicion of prostate cancer. Prostate cancer should be considered a potential risk of testosterone replacement, although many studies have not proven this $(37,39)$. Some studies suggest that if PSA increases above $4.0 \mathrm{ng} / \mathrm{mL}$ or if there is an increase in baseline PSA higher than $1.4 \mathrm{ng} / \mathrm{mL}$, during the next 12 months after beginning of testosterone replacement, a more detailed urological evaluation as well as withdrawal from hormone treatment should be taken into consideration (40). A recent study conducted with Japanese males with late-onset hypogonadism evaluated symptoms related to prostate changes before and after three months of testosterone replacement, based on three different questionnaires. The study confirms that a short period of time of testosterone replacement is safe (41). Another study followed during a mean interval of 33.8 months, with 81 hypogonadal males under hormone replacement, demonstrated that prostate cancer could be identified and treated, and that prostate cancer incidence was not different in individuals undergoing testosterone replacement as compared to the general population (42). On the other hand, corroborating the potential risk of andro- 
genic treatment, one could mention the improvement of prostate cancer patients undergoing androgenic suppression (orchiectomy, GnRH analogs), but these treatments have significant side effects (43). Further studies are needed for better clarifying the actual testosterone replacement therapy risk on prostate tissue (44). Despite various attempts of demonstrating that increased testosterone levels may lead to an increased risk of prostate cancer, there are no convincing scientific evidences supporting this hypothesis. Current consensus report the need for regular prostate followup of males under testosterone replacement therapy, through PSA measurements and digital rectal examination twice or three times during the first year, and afterwards at least once a year. Biopsy should be done chiefly for males with altered PSA or digital rectal examination findings at baseline examination or for those who developed significant changes in these parameters during the course of treatment (45).

\section{CONCLUSIONS}

Our study evaluated testosterone replacement effects over six months on males with late-onset hypogonadism in comparison to hypogonadal males and eugonadal controls supplemented with complex-B vitamins. As benefits of testosterone replacement, we found increase in libido and, in a smaller degree, in sexual potency, evaluated through replies to question 1 of ADAM and the IIEF questionnaire, respectively. Furthermore, testosterone replacement showed to be beneficial by reducing significantly waist circumference, which may be interpreted as a change in body composition and a decrease in cardiovascular risk.

Quality of life did not change among hypogonadal males after six months of testosterone replacement when compared to the other two groups under follow-up.

During the six months of study, no increases in hematocrit or in PSA were noted in males under testosterone replacement therapy that could represent a higher risk of polycythemia, prostate hyperplasia or malignancy related to the treatment.

The present study ratifies the need for well-defined criteria for androgen replacement in late-onset male hypogonadism, since testosterone therapy was capable, in a short period, of improving specific aspects of the clinical picture, such as libido, sexual potency, and waist circumference, the latter representing a marker for metabolic syndrome and its consequences.
Acknowledgements: we are grateful to the Centro de Estudos of the Instituto Nacional de Traumatologia e Ortopedia (Into) for their help in conducting this study. Thanks are also owed to the Hospital da Lagoa Laboratory for carrying out the biochemical dosages from patients, and to the Urology Service, where the patients underwent prostate digital rectal examination. In addition, we thank Mrs. Rosangela Aparecida Martins Noé, M.Sc. in Statistics, from Universidade Federal do Rio de Janeiro, for the statistical analysis.

Disclosure: no potential conflict of interest relevant to this article was reported.

\section{REFERENCES}

1. Wang C, Nieschlag E, Swerdloff R, Behre HM, Hellstrom WJ, Gooren $\mathrm{LJ}$, et alC. Investigation, treatment and monitoring of lateonset hypogonadism in males: ISA, ISSAM, EAU, EAA and ASA recommendations. Eur J Endocrinol. 2008;159(5):507-14.

2. Rosner W, Auchus RJ, Azziz R, Sluss PM, Ralf H. Utility, limitations, and pitfalls in measuring testosterone: an endocrine society position statement. J Clin Endocrinol Metabol. 2007;92:405-13.

3. Juul A, Skakkebaek NE. Androgens and the Ageing male. Hum Reprod Update. 2002;8(5):423-33.

4. Clapauch R, Braga DJC, Marinheiro LP, Buksman S, Schrank Y. Risk of late-onset hypogonadism (andropause) in Brazilian men over 50 years of age with osteoporosis: usefulness of screening questionnaires. Arq Bras Endocrinol Metab. 2008;52(9):1439-47.

5. Clapauch R, Carmo AM, Marinheiro L, Buksman S, Pessoa I. Laboratory diagnosis of late-onset male hypogonadism andropause. Arq Bras Endocrinol Metab. 2008;52(9):1430-8.

6. Morley JE, Charlton E, Patrick P, Kaiser FE, Cadeau P, McCready B, et al. Validation of a screening questionnaire for androgen deficiency in aging males. Metabolism. 2000;49(9):1239-42.

7. Ichioka $K$, Nishiyama $H$, Yoshimura $K$, Itoh N, Okubo K, Terai A. Aging males' symptoms scale in Japanese men atteding a multiphasic health screening clinic. Urology. 2006;67(3):589-93.

8. Heinemann LAJ, Zimmermann T, Vermeulen A, Thiel C, Hummel W. A new aging males synptoms (AMS) rating Scale. Aging Male. 1999;2(2):105-14.

9. Ferraz MB, Ciconelli M. Tradução e adaptação cultural do índice internacional de função erétil para a língua portuguesa. Rev Bras Med. 1998;55(1):35-40.

10. Kaufman JM, Vermeulen A. The decline of androgen levels in elderly men and its clinical and therapeutic implications. Endocr Rev. 2005;26(6):833-76.

11. Vermeulen A, Verdonck L, Kaufman JM. A Critical evaluation of simple methods for the estimation of free testosterone in serum. J Clin Endocrinol Metab. 1999;84(10):3666-72.

12. Picon PX, Leitão CB, Gerchman F, Azevedo MJ, Silveiro SP, Gross JL, et al. Medida da cintura e razão cintura/quadril e identificação de situações de risco cardiovascular: estudo multicêntrico em pacientes com diabetes melito tipo 2. Arq Bras Endocrinol Metab. 2007;51(3):443-9.

13. Laurindo IMM, Ximenes AC, Lima FAC, Pinheiro GRC, Batistela L, Bertolo, et al. Artrite reumatóide: diagnóstico e tratamento. Rev Bras Reuma. 2004;44:435-42.

14. Kazi M, Geraci AS, Koch CA. Considerations for the diagnosis and treatment of testosterone deficiency in elderly men. Am J Med. 2007;120(10):835-40.

15. Margo K, Winn R. Testosterone treatments: Why, when, and how? Am Fam Physician. 2006;73(9):1591-8.

16. Sharma $V$, Peros $P$. The management of hypogonadism in aging male patients. Postgrad Med. 2009;121(1):113-21. 
17. Morley JE. Androgens and aging. Maturitas. 2001;38(1):61-73.

18. Nakhai Pour HR, Emmelot-Vonk MH, Sukel-Helleman M, Verhaar HJ, Grobbee DE, van der Schouw YT. Double blind randomized placebo-controlled trial on the effects of testosterone supplementation in erdely men with moderate to low testosterone levels: design and baseline characteristics. Trials. 2006;7:24.

19. Lunenfeld B, Nieschlag E. Testosterone therapy in the aging male. Aging Male. 2007;10(3):139-53.

20. Gooren LJG, Saad F. Recent insights into androgen action on the anatomical and physiological substrate of penile erection. Asian J Androl. 2006;8(1):3-9.

21. Seftel A. Testosterone replacement therapy for male hypogonadism: Part III. Pharmacologic and clinic profiles, monitoring, safety issues, and potential future agents. Intern J Impot Research. 2007;19(1):2-24.

22. Travison TG, Morley JE, Araujo AB, O'Donnell AB, Mckinlay JB. The relationship between libido and testosterone levels in aging Men. J Clin Endocrinol Metab. 2006;91(7):2509-13.

23. Conaglen JV, Conaglen HM. The effects of treating male hypogonadism on couples' sexual desire and function. J Sex Med. 2009;6(2):456-63.

24. Englert H, Schaefer G, Roll S, Ahlers C, Beier K, Willich S. Prevalence of erectile dysfunction among middle-aged men in a metropolitan area in Germany. Int J Impot Research. 2007;19(2):183-8.

25. Chiang HS, Cho SL, Lin YC, Hwang TI. Testosterone gel monotherapy improves sexual function of hypogonadal men mainly through restoring erection: evaluation by IIEF score. Urology. 2009;73(4):762 -6.

26. Yassin AA, Saad F. Improvement of sexual function in men with late-onset hypogonadism treated with testosterone only. J Sex Med. 2007;4(2):497-501.

27. Bhasin S, Cunningham GR, Hayes FJ, Matsumoto AM, Snyder PJ, Swerdloff RS, et al. Testosterone therapy in adult men with androgen deficiency syndromes: an Endocrine Society Practice Guideline. J Clin Endocrinol Metab. 2006;(10):2005-847.

28. Saad F, Gooren LJ, Haider A, Yassin A. A dose-response study of testosterone on sexual dysfunction and features of the metabolic syndrome using testosterone gel and parenteral testosterone undecanoate. J Androl. 2008;29(1):102-05.

29. Kapoor D, Malkin CJ, Channer KS, Jones TH. Androgens, insulin resistance and vascular disease in men. Clin Endocrinol (Oxf). 2005;63(3):239-50.

30. Kappor D, Jones TH. Androgen deficiency as a predictor of metabolic syndrome in aging men: an oportunity for intervention? Drugs Aging. 2008;25(5):357-69.

31. Laaksonen DE, Niskanen L, Punnonen K, Nyyssonen K, Tuomainen TP, Valkonen VP, et al. The metabolic syndrome and smoking in relation to hypogonadism in middle-aged men: a prospective cohort study. J Clin Endocrinol Metab. 2005;90(2):712-9.
32. La Vignera $S$, Calogero AE, D'Agata R, Di Mauro M, Tumibo S, Condorelli $\mathrm{R}$, et al. Testosterone therapy improves the clinical response to conventional treatment for male patients with metabolic syndrome associated to late onset hypogonadism. Minerva Endocrinol. 2008;33(3):159-67.

33. Smith MR, Lee $H$, Nathan DM. Insulin sensitivity during combined androgen blockade for prostate cancer. J Clin Endocrinol Metab. 2006;91(4):1305-8.

34. Boyanov MA, Boneva Z, Christov VG. Testosterone supplementation in men with type 2 diabetes, visceral obesity and partial androgen deficiency. The Aging Male. 2003; 6(1):1-7.

35. Wygoda MM, Filippo Jr. RB, Gomes MAS, Clapauch R. Monitorizando a terapia de reposição estrogênica (TRE) na menopausa. Arq Bras Endocrinol Metab. 1999;43(5):336-43.

36. Katznelson L, Robinson MW, Coyle CL, Lee Hang, Farrell C. Effects of modest testosterone supplementation and exercise for 12 weeks on body composition and quality of life in erdely men. Eur $\mathrm{J}$ Endocrinol. 2006;155(6):867-75.

37. Rhoden EL, Morgentaler A. Risks of testosterone-replacement therapy and recommendations for monitoring. New Engl J Med. 2004;350(5):482-92.

38. Hajjar RR, Kaiser FEK, Morley JE. Outcomes of long-term testosterone replacement in older hypogonadal males: a retrospective analysis. J Clin Endocrinol Metab.1997;82(11):3793-6.

39. Marks LS, Mazer NA, Mostaghel E, Hess DL, Dorey FJ, Epstein $\mathrm{JL}$, et al. Effect of testosterone replacement therapy on prostate tissue im men with late - onset hypogonadism: a randomized controlled trial. JAMA. 2006;296(19):2351-61.Practice

40. Barqawi A, Crawford ED. Testosterone replacement therapy and risk of prostate cancer. Is there a link? Int J Impot Research. 2006;18(4):323-8.

41. Takao T, Nakayama J, Matsuoka Y, Miyagawa Y, Takada S, Nonomura N, Okuyama A. Lower urinary tract symptoms after hormone replacement therapy in Japanese patients with late-onset hypogonadism: a preliminary report. Int J Urol. 2009;16(2):212-4.

42. Coward RM, Simhan J, Carson CC. Prostate-specific antigen changes and prostate cancer in hypogonadal men treated with testosterone replacement therapy. BJU Int. 2009;103(9):1179-83.

43. Thompson CA, ShanafeltTD, Loprinzi CL. Andropause: symptom management for prostate cancer patients treated with hormonal Ablation. Oncologist. 2003;8(5):474-87.

44. Gould DC, Kirby RS. Testosterone replacement therapy for late onset hypogonadism: what is the risk of inducing prostate cancer? Prostate Cancer Prostatic Dis. 2006;9(1):14-8.

45. Morgentaler AMD. Testosterone replacement therapy and prostate risks: Where's the beef? Canad J Urol. 2006;13 Suppl 1:40-3. 